\title{
TOXINA BOTULÍNICA APLICADA PARA FINS TERAPÊUTICOS
}

\author{
Elisângela Costa Xavier ${ }^{1}$ \\ Leonardo Guimarães de Andrade² \\ Livia Cabral Lobo ${ }^{3}$
}

RESUMO: Clostridium botulinum é um organismo gram-positivo estritamente anaeróbio e forma esporos, produz uma potente neurotoxina chamada Toxina Botulínica tipo A (TBA), que é eficaz para pacientes durante o tratamento e procedimentos. A qualidade de vida desempenha um papel extremamente eficaz e é um dos métodos não cirúrgicos mais utilizados no Brasil. Injetar intramuscularmente onde você deseja resultados, o TBA se liga a receptores terminais nos nervos motores, inibe a liberação de acetilcolina e, em última análise, evita a contração muscular, resultando em relaxamento muscular temporário. Portanto, foi usado clinicamente por Allan Scott, oftalmologista da Califórnia (EUA), para correção de estrabismo na década de 1980. Em seguida, ocorreram movimentos involuntários como blefaroespasmo e espasmo hemifacial, tornando-se a primeira escolha para o tratamento dessas doenças. Mais tarde, foi usado para distonia cervical, distonia espástica, distonia focal das mãos e pernas, distonia motora específica e tremor. Nos últimos anos, o escopo de indicações para o tratamento da toxina botulínica aumentou significativamente e agora é usado para tratar espasmos, programas de reabilitação, disfunção da bexiga ou do esfíncter anal, dores de cabeça tensionais e até mesmo como um tratamento cosmético para eliminar rugas faciais. A Toxina botulínica do tipo A também é usada como tratamento para enxaqueca crônica e hiperidrose e é uma opção de tratamento alternativo para cirurgia em certas condições patológicas.

Palavras-chave: Toxina Botulínica tipo A. Usos terapêticos. Hiperidrose. Estratibismo. Enxaqueca crônica.

ABSTRACT: Clostridium botulinum is a strictly anaerobic, spore-forming grampositive organism, producing a potent neurotoxin called Botulinum Toxin Type A (TBA), which is effective for patients during treatment and procedures. Quality of life plays an extremely effective role and is one of the most used non-surgical methods in Brazil. Injecting intramuscularly where you want results, TBA binds to terminal

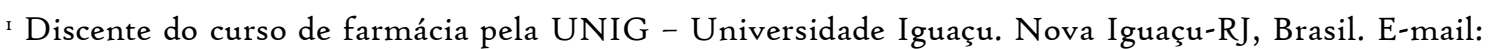
zamzarj@hotmail.com.

${ }^{2}$ Mestre em Ciências do Meio Ambiente na Universidade Veiga de Almeida. Faz parte do corpo docente da Universidade Iguaçu no Estado do Rio de Janeiro. E-mail: leonard.gui@hotmail.com

3 Professora e orientadora do curso de farmácia pela UNIG - Universidade Iguaçu Nova Iguaçu-RJ, Brasil.
} 
receptors on motor nerves, inhibits the release of acetylcholine, and ultimately prevents muscle contraction, resulting in temporary muscle relaxation. Therefore, it was used clinically by Allan Scott, an ophthalmologist from California (USA), to correct strabismus in the 1980 os. Then, involuntary movements such as blepharospasm and hemifacial spasm occurred, making it the first choice for the treatment of these diseases. It was later used for cervical dystonia, spastic dystonia, focal hand and leg dystonia, specific motor dystonia, and tremor. In recent years, the scope of indications for botulinum toxin treatment has increased significantly and is now used to treat spasms, rehabilitation programs, bladder or anal sphincter dysfunction, tension headaches and even as a cosmetic treatment to eliminate wrinkles. facials. Botulinum toxin type $\mathrm{A}$ is also used as a treatment for chronic migraine and hyperhidrosis and is an alternative treatment option to surgery for certain pathological conditions.

Keywords: Botulinum Toxin type A. Therapeutic uses. Hyperhidrosis. Strabismus. Chronic migraine.

\section{INTRODUÇÃO}

Ao longo dos anos, a Toxina Botulínica $(\mathrm{T} \times \mathrm{B})$ foi assumindo diversas aplicações, que evoluíram e trouxeram novas chances à Medicina. Conhecida há séculos como uma droga mortal, a Toxina Botulínica, hoje, é utilizada em um grande número de especialidades médicas, sendo uma droga altamente potente, introduzindo um princípio terapêutico completamente diferente (MARQUES, 2014).

A Toxina Botulínica é criada a partir da fermentação da bactéria Clostridium botulinum, microrganismo que foi isolado pela primeira vez no fim do século XVIII. Essa toxina foi a primeira toxina microbiana utilizada para tratamento de doenças. A bactéria é capaz de criar sete sorotipos da toxina classificadas de A a G, sendo os estudos, comercialização e aplicações terapêuticas da toxina voltadas para a utilização do tipo A, por conta do seu crescimento na cultura e cristalização em uma forma estável, permitindo a purificação de forma eficaz, garantindo assim a utilização de forma preservada (SILVA, 20II).

A ação da Toxina Botulínica tipo A inicia com 3 a 5 dias após aplicação com tempo aproximadamente 6 meses, e gradativamente a ação começa a diminuir após o terceiro mês, sendo que em algumas patologias o tempo de ação pode variar (COLHADO et al., 2009). 
Hoje, a Toxina Botulínica tipo A é muito utilizada no tratamento de estrabismo, enxaqueca e hiperidrose, sendo o médico responsável por indicar o intervalo de tempo que as aplicações são feitas, uma vez que a ação de paralisação do músculo na região tratada pela toxina é temporária (SILVA, 20II).

\section{2- OBJETIVOS}

\section{I- OBJETIVO GERAL}

Revisar o histórico, as propriedades farmacológicas e aplicações clínicas da Toxina Botulínica, quando empregada para fins terapêuticos.

\section{2- OBJETIVOS ESPECÍFICOS}

- Efetuar uma revisão de literatura a respeito das indicações para fins terapêuticos da utilização da Toxina Botulínica do tipo A.

- Explicar a utilização da Toxina Botulínica tipo A para fins terapêuticos.

- Descrever seu mecanismo de ação.

- Apontar as principais doenças em que a toxina pode ser utilizada para tratamento.

- Destacar a utilização da Toxina Botulínica, por se tratar de um procedimento não invisível e de resultado imediato.

\section{3- JUSTIFICATIVA}

A Toxina Botulínica, uma das mais potentes toxinas bacterianas conhecidas, tem ação terapêutica eficaz no tratamento de algumas síndromes dolorosas. Entretanto, algumas de suas indicações ainda estão em fase de comprovação com relação a sua eficácia.

\section{4- METODOLOGIA}

O presente artigo incluiu inicialmente um extenso levantamento bibliográfico, elaborado a partir de materiais publicados selecionados de artigos científicos. $\mathrm{O}$ artigo opta por adotar o método de revisão de literatura. Essas informações podem ser encontradas em plataformas como Scielo, LILACS, Pubmed e Ministério da Saúde do Brasil. Também selecionei alguns artigos com as palavras chaves Toxina Botulínica, 
Clostridium botulinum, e tratamento, desde o primeiro relatório até a publicações recentes, para descrever o uso da toxina para fins terapêuticos.

\section{5- REVISÃO DE LITERATURA}

\section{I- TOXINA BOTULINICA}

A história da Toxina Botulínica $(\mathrm{T} \times \mathrm{B})$ tem origem quando em 1817 foi publicada primeira descrição do botulismo (ou seja, envenenamento pela Toxina Botulínica). $\mathrm{O}$ autor, Justinus Kerner, associou mortes resultantes de intoxicação com um veneno encontrado em salsichas defumadas (do latim botulus que significa salsicha). Kerner propôs uma variedade de potenciais usos da Toxina Botulínica na Medicina, principalmente em desordens de origem no sistema nervoso central que, atualmente, através de novas pesquisas vêm sendo comprovadas (WENZEL, 2004).

A toxina botulínica é um agente biológico formado naturalmente pelos agentes bacterianos anaeróbicos gram positivos, conhecido como Clostridium botulinum, dos quais quando entram em contato com os músculos da face, passam a ter comunicação direta com as terminações nervosas, causando a imobilização dos canais onde possuem cálcio, inibindo a passagem da acetilcolina e por resultado desse efeito biológico que promove o repouso ou paralisação do músculo alvo de forma passageira (OKAJIMA, 2013).

Embora todos os sorotipos inibam a liberação de acetilcolina na terminação nervosa, suas proteínas intracelulares, seus mecanismos de ação e suas potências variam substancialmente. O sorotipo mais amplamente estudado para o propósito terapêutico é o A, entretanto, os estudos sobre os efeitos dos demais sorotipos estão em crescimento.

Em 1978, Alan Scott conduziu os primeiros testes com a Toxina Botulínica-A injetada em seres humanos para o tratamento de estrabismo. Posteriormente sua indicação se estendeu para as distonias segmentares, tremores e outros movimentos anormais (LANG,2004).

O uso da Toxina Botulínica no tratamento da espasticidade foi feito pela primeira vez em 1989, onde foi publicado o resultado de sua aplicação em músculos 
intensamente espásticos de seis pacientes adultos com hemiplegia secundária ao infarto cerebral. Os neurologistas perceberam a potencial utilidade da Toxina Botulínica em desordens neurológicas envolvendo excessiva contração ou tônus musculares (AGUILAR, 200I).

Utiliza-se a unidade internacional (UI) para definir a potência biológica de todas as preparações de Toxina Botulínica, sendo uma unidade internacional a quantidade de Toxina Botulínica capaz de matar (em experimentos) a metade de uma população de ratos (DL5o) (WOHLFARTH et al., 2004).

\section{2- MECANISMO DE AÇÃO}

O processo de recomposição fisiológica de modo normalmente acontece gradativamente, no período estimado entre dois a três meses depois de sua aplicação. Desta forma, percebe-se que a restituição da estagnação decorrente da paralisação dos músculos decorre por meio de mecanismos sendo eles: o brotamento neural, onde surgi novos brotos axonais e a reinervação da região onde ocorre a formação de novas placas de terminações menores. O músculo onde passou pelo procedimento passa por regeneração por conta das proteínas presentes nas vesículas de acetilcolina do qual comumente é reconstituída entre um e quatro meses (CALZA, et al., 2015).

Após a aplicação da Toxina Botulínica do tipo A, seu resultado começa a ser iniciado depois das 24 a 48 horas após os procedimentos injetáveis. Referente aos aspectos clínicos é observado paralisia expressiva após as primeiras 48 horas podendo chegar até os io dias, sendo que o resultado mais expressivo acontece na segunda semana pós o procedimento ser realizado. Novos elementos interligados SNARE (soluble NSF attachment receptor) começam a se formar depois de 2 a 3 meses da aplicação, dado que neste espaço de tempo as cadeias mais leves da toxina encontramse inertes e as extremidades nervosas restauram sua funcionalidade. Deste modo, a efetividade da aplicação injetável da Toxina Botulínica do tipo A permanecem em média 3 meses (KANE \& SATTLER, 2016).

A localidade respectiva da aplicação deve ser estudada e estabelecida, pois o local estabelecido e a concentração da sua dosagem são diretamente correlacionadas com o 
tempo médio da durabilidade e eficácia da Toxina Botulínica tipo A. Sua atuação em potencial máximo é expressiva entre a primeira semana podendo chegar até os I4 dias sendo sua duração estabelecida até seis meses, dependendo de qual produto e a técnica que irá ser utilizada (SPOSITO \& TEIXEIRA, 2014).

\section{3- AÇÃO SOBRE A LIBERAÇÃO DA ACETILCOLINA}

A Toxina Botulínica é uma neurotoxina que possui alta afinidade pelas sinapses colinérgicas, ocasionando um bloqueio na liberação de acetilcolina desses terminais nervosos, contudo, sem alterar a condução neural de sinais elétricos ou a síntese e armazenamento de acetilcolina. A injeção muscular de Toxina Botulínica, na localização apropriada, provoca desnervação química parcial e diminuição da contratura, sem ocasionar paralisia completa. Quando esse tecido é glandular tem-se o bloqueio da secreção (UNNO et al., 2005).

A aplicação local intramuscular de uma diluição selecionada de Toxina Botulínica é seguida de difusão rápida no espaço intersticial, depositando-se, especificamente, nas terminações nervosas motoras dos músculos esqueléticos (placa neuromuscular).

A inibição da liberação de acetilcolina pela Toxina Botulínica ocorre em processo de múltiplas etapas. Inicialmente, a Toxina Botulínica liga-se aos receptores de membrana pré-sináptica do terminal nervoso motor de maneira irreversível. Essa especificidade ao local de ligação garante à Toxina Botulínica alta seletividade para sinapses colinérgicas. Logo, os receptores pré-sinápticos são responsáveis pela endocitose da neurotoxina para o terminal nervoso motor. Após a interiorização da molécula, a mesma é separada em duas cadeias polipeptídicas por proteases presentes no terminal nervoso motor. Essa clivagem da Toxina Botulínica é considerada o passo decisivo para sua ativação (BRATZ et al., 2015).

Após a clivagem, a cadeia leve é transcolada através da membrana da vesícula endocítica para dentro do citosol e se liga com alta especificidade ao complexo proteico SNARE. O alvo proteico também varia conforme o sorotipo de Toxina Botulínica. Atuando como enzimas, as cadeias leves de cada um dos sete sorotipos clivam uma 
ligação peptídica distinta em um ou mais pontos das proteínas SNARE, de tal forma que nenhum dos sorotipos atua exatamente no mesmo local, o que faz com que suas características de ação e suas potências variem substancialmente, embora todos os sorotipos apresentem o mesmo efeito final: inibição da liberação de acetilcolina na terminação nervosa (SETLER, 2002).

A clivagem proteolítica do complexo SNARE realizada pela cadeia leve da Toxina Botulínica previne a ancoragem da vesícula sináptica na superfície interna da membrana celular, resultando assim no bloqueio da fusão vesicular, efeito este que impede a liberação de acetilcolina, induzindo paralisia flácida nas fibras musculares atingidas (desnervação química). Com isso, a ação clínica evidente é a fraqueza ou paralisia dose-dependente no músculo esquelético nas terminações nervosas motoras (DRESSER et al., 2005).

\section{4- CONTROLE DE QUALIDADE NA PRODUÇÃO DA TOXINA}

A toxina botulínica é um produto farmacêutico biológico, isto é, derivado de um organismo vivo, portanto, não é possível dizer que as Toxinas Botulínicas são exatamente iguais, pois nem mesmo um frasco de toxina tipo A de lotes diferentes da mesma marca são iguais, porém, existe uma equivalência clínica, ou seja, a toxina deve produzir o mesmo efeito terapêutico que outra. Para provar que a toxina possui o efeito clínico desejado, devem ser realizados 4 fases de estudos clínicos assegurando a segurança e efetividade da mesma. São realizados estudos pré-clínicos in vivo e que avaliam a eficácia, efeitos colaterais, toxicologia aguda e subaguda da toxina. Após isso, a farmacocinética e segurança específica para alguns sistemas são estudados. Com esses dados, iniciam-se os estudos em humanos onde as 4 fases são divididas da seguinte forma:

$\checkmark$ Fase I: estudos realizados em voluntários humanos sadios que determinam a segurança, efeitos colaterais, farmacocinética e limite de doses.

$\checkmark$ Fase II: Avaliação da eficácia em pacientes. 
$\checkmark$ Fase III: Estudos multicêntricos que verificam os efeitos colaterais, interações medicamentosas e os efeitos causados pela droga quando utilizada em uma população maior e mais heterogenia, calculando as vantagens e limitações.

$\checkmark$ Fase IV: Estudos após o registro do produto, para melhorar o conhecimento sobre ele, auxiliando na farmacovigilância (FONSECA, 2008).

A ANVISA concedeu a autorização do uso de toxina botulínica para o tratamento de enxaqueca. Ela afirma que desde 2006, estudos realizados por cientistas de Taiwan apontam que o tratamento com a toxina melhorou a frequência $e$ intensidade das crises em até 60\% dos pacientes testados. Segundo a agência, medicamentos biológicos são muito complexos e possuem um peso molecular superior aos medicamentos sintéticos e semissintéticos, sua caracterização química também é mais difícil, exigindo um processo de produção longo e complicado. Esses medicamentos não podem ser copiados de fabricante para fabricante, portanto não existem medicamentos biológicos genéricos embora o termo biogenérico seja encontrado na literatura médica. O conceito de bioequivalência não está estabelecido, pois critérios farmacocinéticos não são relevantes ou não podem ser medidos. O termo biossimilar ou follow-up biológicas são utilizados para descrever toxinas botulínicas de procedências diferentes como, por exemplo, fabricantes diferentes. Como a similaridade dos medicamentos biológicos não é aceita pela ANVISA, todos os medicamentos biológicos, para serem registrados, devem ser submetidos a estudos préclínicos e clínicos de forma independente para cada indicação terapêutica o que não ocorre nos medicamentos genéricos, onde seu registro pode ter base em seu medicamento de referência contanto que sua bioequivalência e equivalência farmacêutica seja comprovada. A dose e a duração do efeito podem variar de acordo com o produto. As diferenças entre as toxinas, limitam a intercambilidade entre elas, portanto, a troca de marca ou fabricante pode não ser possível em algumas situações. Para registrar um medicamento biológico novo ou não, a empresa deve realizar ensaios clínicos, preferencialmente randomizados e controlados que evidenciem a qualidade, eficácia e segurança do medicamento. A validade do registro é de 5 anos e para renová-lo a eficácia e segurança são reavaliados. No caso de suspeitas 
reações adversas, os profissionais de saúde devem notificar o caso para a Gerência de farmacovigilância para que seja possível realizar investigações e para tomar as devidas medidas sanitárias (ANVISA, 2007).

\section{5- APLICAÇÕES CLÍNICAS}

Em 1990, o NIH (National Institutes of Health) emitiu um consenso considerando o uso clínico da Toxina Botulínica:

$\checkmark$ A Toxina Botulínica é segura e efetiva no tratamento de estrabismo e no tratamento sintomático do blefaroespasmo essencial, espasmo hemifacial, disfonia espasmódica do adutor, bruxismo, apertamento dentário, distonia mandibular e distonia cervical (indicações atuais aprovadas pelo Food and Drug Administration); todas as outras são usadas ainda sem regulamentação definitiva pelo FDA.

$\checkmark$ A Toxina Botulínica é promissora para o tratamento de outras condições, entretanto estudos adicionais são necessários como nas seguintes desordens: distonia focal e segmentar, incluindo distonia das mãos e membros, hipercontratilidade do esfíncter interno anal, dissinergia do detrussor (usualmente consequência de lesão da medula espinhal), espasticidades, disfonia espasmódica do abdutor, tremor vocal e gagueira.

$\checkmark$ Estudos clínicos adicionais são encorajados para elucidar muitas questões sem resposta sobre a Toxina Botulínica e seus usos terapêuticos (LANG,2004).

Estudos com a Toxina Botulínica A formaram a base para tal referência. Rapidamente depois, a Toxina Botulínica B foi introduzida nos estudos clínicos para distonia cervical e foi provada sua efetividade e segurança. O uso da Toxina Botulínica para distonia focal tornou-se difundido. Relatos da eficácia em espasticidade e outras condições neurológicas seguiram-se. A segurança da terapia com Toxina Botulínica tem permitido seu uso em estética, hiperidrose, sialorreia, dor tensional, entre outras. A eficácia em cada uma dessas aplicações pode ser prontamente explicada através do efeito da Toxina Botulínica na neurotransmissão colinérgica (PORTA, 200o). 
Atualmente, a Toxina Botulínica A tem sido usado para tratar mais de um milhão de pacientes em todo mundo e seu uso clínico foi aprovado em 73 países. Essas aprovações incluem o tratamento da paralisia cerebral juvenil em 52 países e espasticidade adulta em 36 países, embora essas indicações não estejam regulamentadas nos EUA. Outros usos sem regulamentação do Toxina Botulínica A nos EUA incluem cefaleias primárias como a migrânea, dor miofacial, acalásia, desordens de sudorese excessiva e sialorreia associada a condições como paralisia cerebral e doença de Parkinson (SILVA, 20II).

Há 20 anos, a Toxina Botulínica A tem sido usada para o tratamento de uma variedade de desordens caracterizadas pelo aumento patológico da contração (tônus) muscular. Correntes de pesquisa se esforçam em focar novas áreas para aplicação da Toxina Botulínica em terapias dolorosas específicas, particularmente em cefaleias primárias e síndrome dolorosa miofacial cervical, da cintura escapular e dorso. Estes estudos embasam novas opções para pacientes com síndromes dolorosas resistentes a tratamentos atualmente disponíveis (WENZEL, 2004).

O tratamento adjuvante com fisioterapia é importante para maximizar os benefícios da Toxina Botulínica. Alongamento passivo tem benefício particular imediatamente após as injeções de Toxina Botulínica, assim como o relaxamento muscular por massagem profunda e aumento da amplitude de movimento dos músculos, tendões e ligamentos. Uma vez que a dor se torna tolerável, exercícios ativos de alongamento podem ser iniciados. O objetivo destes exercícios é alcançar reeducação neuromuscular, quebrando o ciclo espasmo dor, amplificado por sensibilização central. Então, a postura e a mecânica articular devem melhorar e reflexos tediosos normais podem ser restabelecidos (SHEERAN, 2002).

As primeiras publicações de estudos clínicos com Toxina Botulínica A foram em dor miofascial, desordens na região da articulação temporomandibul, dor facial e cefaleia tipo tensão. $\mathrm{O}$ número de casos era pequeno e os resultados contraditórios. $\mathrm{O}$ aumento da evidência de eficácia foi recentemente obtido com estudos placebocontrolado, duplamente encobertos e com distribuição aleatória dos pacientes e com grande número de casos. Baseado nas propriedades relaxantes musculares, a Toxina 
Botulínica A tem sido usada para tratar uma variedade de condições musculares incluindo desordens do trato digestivo superior, cosmético, desordens geniturinárias, espasticidade, distonia cervical e blefaroespasmo. Mais especificamente com relação à dor, várias publicações têm demonstrado a eficácia e segurança da Toxina BotulínicaA no tratamento da cefaleia tipo tensão, migrânea, dor lombar crônica e dor miofascial (KLEIN, 2004).

\section{6- UTILIZAÇÃO DA TOXINA BOTULINICA PARA FINS TERAPÊUTICOS 5.6.I- ESTRABISMO}

O estrabismo é conhecido como qualquer desvio do globo ocular, que ocasiona uma desfocalização em relação ao ponto de fixação, devido a hiperatividade de um ou mais músculos que controlam a posição dos olhos, hoje, embora se saiba o que é, ainda não existe uma definição padronizada para o estrabismo, devido à complexidade da alteração. Logo, o estrabismo é classificado de acordo com o ângulo do desvio em relação ao que se está olhando, e pode ser classificado como: esotropia (para dentro); exotropia (para fora); hipertropia (para cima) e hipotropia (para baixo). Pode acontecer em qualquer faixa etária, e quando afeta indivíduos nas idades iniciais, pode acarretar prejuízo de desenvolvimento da visão, já nos adultos, normalmente é uma manifestação secundária a alguma alteração já existente, como doença vascular, neurológica, entre outras (SHIMAUTI et al., 2012).

O diagnóstico deve ser realizado de forma precoce, permitindo assim um tratamento eficaz, e este deve ser determinado apenas por um oftalmologista. Uma das formas de tratamento existente para o estrabismo é a toxina botulínica tipo A (SUGANO, 2013).

Os primeiros testes com a Toxina Botulínica tipo A para tratamento de estrabismo, teve início em 1978, pelo médico oftalmologista Alan Scott, e no ano de 1989 foi aprovado seu uso como método de tratamento, sendo considerada a melhor

droga para causar paralisação do músculo extraocular, provendo assim o alinhamento do globo ocular, passando a ser um método alternativo ao Cirúrgico (MARQUES, 2014). 
A ação da Toxina Botulínica tipo A vai proceder na terminação nervosa muscular, onde o transporte de cálcio será bloqueado, e uma vez que não tem cálcio, a acetilcolina não é liberada na porção pré-sináptica, de modo que o músculo não consegue contrair, permitindo o alinhamento dos eixos visuais durante a o período de ação da droga (COLHADO et al., 2009).

A Toxina Botulínica possui uma ação gradativa e tem duração de aproximadamente 6 meses. Por agir na terminação nervosa, quando a ação da Toxina Botulínica se encerra, ocorre regeneração das fibras e o músculo ocular pode voltar a contrair, e o alinhamento regredir, por conta disso, torna-se necessária a reavaliação após aplicação (SUGANO, 2013).

\subsection{2- ENXAQUECA}

A enxaqueca se manifesta de forma recorrente como um tipo de dor de cabeça intensa, muitas vezes acompanhada de vômito e náusea, devido à dor. A crise ocorre normalmente a cada 45 dias e a duração varia entre 24 a 48 horas. Acomete homens e mulheres, sendo mais comum nas faixas etárias de 18-29 anos e 40-49 anos, com maior incidência nas mulheres (WANNMACHER \& FERREIRA, 2004).

A enxaqueca em sua forma crônica é caracterizada por episódios de cefaleias que acontece em is ou mais dias no mês, por três meses ou mais, com sintomas de enxaqueca por pelo menos 8 dias desse período. É considerada grave, por ser altamente incapacitante, acarretando um impacto significativo na qualidade de vida do indivíduo (TAVARES, 2017).

A fisiopatologia da enxaqueca ainda é pauta de muita discussão no âmbito médico, contudo, a sensibilização central e periférica parece ter um papel importante no desenvolvimento. Sabe-se que a enxaqueca inicia quando as células nervosas excitadas, respondem a uma alteração normalmente externa, enviando impulsos para os vasos sanguíneos, causando sua constrição, seguida de uma dilatação, com liberação de prostaglandinas, serotonina e outras substâncias inflamatórias que causam a dor (GOMES, 2012). 
Os principais fatores de risco envolvidos na enxaqueca são: idade, gênero, condição socioeconômica desfavorável, predisposição genética, de determinados medicamentos, entre outros (TAVARES, 2017).

Uma vez estabelecido o diagnóstico de enxaqueca, principalmente a crônica, medidas de prevenção e tratamento são fundamentais, para tentar amenizar, e até mesmo evitar que ocorra uma nova crise. Uma das opções para o tratamento aprovada pela FDA, desde 2oro, é o uso da Toxina Botulínica tipo A, para enxaqueca crônica (GOMES, 2012).

Após aplicação, a Toxina Botulínica tipo A vai agir na sensibilização periférica, inibindo a liberação de substância $\mathrm{P}$ pelos nervos sensitivos, de glutamato e outros neurotransmissores e neuropeptídeos, responsáveis por causar excitação das células nervosas e desencadear processos inflamatórios, reduzindo indiretamente a sensibilização central, levando a diminuição da dor (TAVARES, 2017).

Os músculos de aplicação da toxina para tratamento são: prócero, corrugador, frontal, temporal, occipital, trapézio e cervical póstero-superior (MENEZES, 2007).

Segundo a literatura, a aplicação da toxina como medida preventiva de enxaqueca apresenta grande eficácia, o uso em pacientes com enxaqueca crônica gerou uma diminuição e em alguns casos a eliminação durante o efeito da toxina, ocasionando melhoria na qualidade de vida. A ação da toxina no tratamento da enxaqueca é de aproximadamente três meses (TAVARES, 2017).

\subsection{3- HIPERIDROSE}

A sudorese é essencial para o equilíbrio da temperatura corporal, a hiperidrose é caracterizada pelo excesso da sudorese, que pode ser classificada como hiperidrose primária e secundária, ocasionada por alterações idiopáticas, podendo ser manifestar de forma crônica, devido à hiperatividade do Sistema Nervoso Autônomo Simpática, que leva a hipersecreção das glândulas sudoríparas (REIS, et al., 20II).

A classificação da hiperidrose primária consiste em causas fisiológica, endócrina e metabólica, uso abusivo de drogas e neoplasias, já a hiperidrose secundária está associada a doenças cardiovasculares e respiratórias, obesidade, infecção crônica, 
distúrbios psiquiátricos e estado febril. A forma de manifestação da hiperidrose causa constrangimento, incômodo e alterações psicológicas, por ser notável a presença de odor. $\mathrm{O}$ excesso da sudorese pode acometer várias regiões, como pode se manifestar em somente uma, quando ocorre em mais de uma região é chamado hiperidrose associada. As regiões de manifestações da hiperidrose são principalmente a axila, palmas e plantas dos pés, locais onde estão localizadas as glândulas écrinas, principal glândula sudorípara do corpo. Acometem homens e mulheres, e pode ocorrer em todas as faixas etárias, principalmente na adolescência, cerca de 30\% a 50\% dos casos relatam histórico familiar e o diagnóstico é exclusivamente clínico (ALVES \& LUBI, 20ıo).

O tratamento mais usado é a utilização de antitranspirantes, mas pode não ser suficiente em determinados casos de hiperidrose, o método cirúrgico causa a remoção das glândulas sudoríparas de forma definitiva. Um novo método no qual engloba a aplicação de Toxina Botulínica tipo A, está sendo muito utilizado por ser de extrema eficiência, a Toxina Botulínica tipo A bloqueia temporariamente a liberação do neurotransmissor acetilcolina, ao impedindo que seja liberado na fenda sináptica, e com isso as glândulas sudoríparas passa a não receber estímulo para a secreção. É considerado um método fácil e pode ser aplicado com anestesia tópica ou local, possui um efeito terapêutico temporário de até 7 meses de duração (SOARES, 2015).

Para o procedimento é usado uma seringa com agulha bem fina, onde são aplicadas pequenas doses da toxina próximo a glândula sudorípara, as aplicações são feiras com a distância de $1,5 \mathrm{~cm}$ a fim de que todas as glândulas sejam alcançadas (REIS, et al., 2011).

A aplicação da Toxina Botulínica tipo A não cura a hiperidrose, por ter ação temporária, e são necessárias novas aplicações em intervalos de tempo determinado pelo profissional, para evitar a volta dos sintomas (ALVES \& LUBI, 2010).

\section{CONCLUSÃO}

Conhecida como veneno, esta é a primeira descrição da Toxina Botulínica. No entanto, estudos com a Toxina Botulínica mostram que os "venenos" selecionados e 
modificados em laboratório são fármacos importantes para o tratamento de algumas doenças que envolvem o sistema nervoso central.

O Toxina Botulínica tipo A é atualmente o mais pesquisado e utilizado para fins terapêuticos, possui alto efeito curativo, boa tolerância ao paciente, a técnica por ser simples e rápida, apresenta vantagens sobre outros métodos de tratamento para certas patologias, sendo considerada um grande avanço na medicina, como no tratamento de estrabismo, enxaqueca e hiperidrose, sendo que em determinadas situações é um método alternativo ao cirúrgico.

A Toxina Botulínica atua na fenda sináptica evitando a liberação do neurotransmissor acetilcolina, causando paralisia muscular temporária na área tratada por cerca de seis meses.

Portanto, podemos concluir que, entre as opções disponíveis, a Toxina Botulínica tipo A vem ganhando credibilidade há décadas. Embora temporária, é uma opção de tratamento eficaz, e, ainda que não seja uma característica do tratamento determinístico, é uma opção segura, de fácil aplicação e elevada satisfação do paciente,

permitindo o retorno ás atividades profissionais no mesmo dia, sendo raras as suas complicações e, caso ocorram, são de caráter temporário e reversível, pouco frequentes e regridem sem deixar sequelas.

\section{REFERÊNCIAS BIBLIOGRÁFICAS}

I- Aguilar-Rebolledo F, Hernandez-Sanchez J, Rayo-Mares D et al.- Toxina botulínica como tratamiento de la espasticidad y distonia en la parálisis cerebral infantil. Gac Méd Mex 2001;137:403-4II

2- Alves MS, Lubi NC. Hiperidrose, causas e tratamento, [Online] 2010. Disponível em: http://tcconline.utp.br/media/tcc/2017/o5/HIPERIDROSE-CAUSAS-ETRATAMENTO.pdf 
3- ANVISA (Brasília). Toxinas botulínicas tipo A: Anvisa esclarece questões ligadas à qualidade dos produtos registrados no Brasil, a indicações terapêuticas e à intercambiabilidade entre elas. Disponível em: http://portal.anvisa.gov.br/wps/content/Anvisa+Portal/Anvisa/Pos++Comercializ acao++Pos++Uso/Farmacovigilancia/Alertas+por+Regiao+Geografica/INFORMES /Informes+de+2007/Informe+GFARM+n+6+de+20+de+julho+de+2007

4- Calza SC, et al. Tratamento do sorriso gengival com toxina botulínica tipo A: relato de caso. RFO UPF, 2015; 20(1о): 8I-87.

5- Colhado OCG, Boeing M, Ortega LB. Toxina botulínica no tratamento da dor. [Internet]Rev. Bras. Anestesiol. Campinas. 2009; 59(3):366-381. Disponível em: http://www.scielo.br/scielo.php?script=sci_arttext\&pid=So03470942009000300013\&1 $\mathrm{ng}=\mathrm{en} \& \mathrm{nrm}=$ iso

6- Dressler D, Saberi FA, Barbosa ER - Botulinum toxin: mechanisms of action. Arq Neuropsiquiatr 2005; 63:180-185.

7- Dias F de LD. O efeito da toxina botulínica tipo a associada ao ácido hialurônico no rejuvenescimento facial. Monografia. [Internet]. Faculdade Sudoeste Paulista Itapetininga-SP, 2017. Disponível em: http://unifsp.edu.br/itapetininga/wpcontent/uploads/2018/o9/ADRIANAFURQUIM-DELIMA-DIAS.pdf

8- Gomes MJM. Alodínia na enxaqueca e as suas implicações no tratamento, [Dissertação]. [Internet]. Faculdade De Medicina Da Universidade De Coimbra, 2012.

\section{Disponível}

em:https://estudogeral.sib.uc.pt/bitstream/ı03ı/8oı //1/Alod\%C3\%ADnia\%2ona\% 
20Enxaqueca\%20e\%20as\%20suas\%20Implica\%C3\%A 7\% $3 \%$ B5es\%20no\%20 Tratame nto.pdf.

9- KANE M, SATTLER G. Guia ilustrado para infiltrações estéticas com toxina botulínica: base, localização, utilidades. São Paulo: Di Livros, 2016.

Io- Klein AW. The therapeutic potential of botulinum toxin. Dermatol Surg 2004; 30:452-455.

II- Lacordia MHFA, et al. Estudo comparativo da ação da toxina botulínica tipo A e da crotoxina sobre as células satélites da musculatura extrínseca ocular em modelo animal. [Internet]Rev. bras. oftalmol., Rio de Janeiro. 2009; 68(5):296-303. Disponível em:

http://www.scielo.br/scielo.php?script=sci_arttext\&pid=So03472802009000500008\&1 $\mathrm{ng}=\mathrm{en} \& \mathrm{nrm}=$ iso

12- Lang A .History and uses of BOTOX (botulinum toxin type A). Lippincott's Case Manag 2004; 9:109-II2.

13- Marques JRS. A Toxina Botulínica: O seu uso clínico, 2014. Biblioteca Digital [Online] [Citado em: 20 out. 2018]. Disponível em:https://bdigital.ufp.pt/bitstream/10284/4851/r/PPG_24363.pdf

I4- Menezes $C$, et al., Botulinum toxin type $A$ in refractory chronic migraine: an openlabel trial. [Internet]. Arq. Neuro-Psiquiatr., São Paulo. 2007; 65(3 $\left.3^{\mathfrak{a}}\right): 596-598$. Disponível em: http://www.scielo.br/scielo.php?script=sci_arttext \&pid=Soo04282X2007000400009\& $\operatorname{lng}=$ en $\& n r m=$ iso

15- Okajima M. Toxina botulínica: da terapia a estética. Ident, 2013 
16- Porta M. A comparative trial of botulinum toxin type $A$ and methilprednisolone for the treatment of myofascial pain syndrome and pain for chronic muscle spasm. Pain 2000; 85:I01-10

I7- Posito MM de M. Toxina Botulínica do Tipo A: mecanismo de ação [Internet]. 2009. Revista Acta Fisiatrica, São Paulo, v. I6, n.oI, p 25 - 37. Disponível em:http://www.actafisiatrica.org.br/detalhe_artigo.asp?id=II9

I8- Reis GMD dos, Guerra ACS, Ferreira JPA. Estudo de pacientes com hiperidrose, tratados com toxina botulínica: análise retrospectiva de to anos. [Internet]. Rev. Bras. Cir. Plást., São Paulo. 20II; 26(4):582-590. Disponível em: http://www.scielo.br/scielo.php?script=sci_arttext\&pi $\mathrm{d}=\mathrm{S}_{1983-}$ $51752011000400008 \& \operatorname{lng}=$ en $\& n r m=$ iso

19- Setler PE. Therapeutic use of botulinum toxins: background and history. Clin J Pain 2002;18(6 suppl):si19-I24.

20- Sheeran G. Botulinum toxin for the treatment of musculoskeletal pain and spasm. Curr Pain Headache Rep 2002; 6:460-469.

21- Shimauti AT, et al., Estrabismo: detecção em uma amostra populacional e fatores demográficos associados.Arq. Bras. Oftalmol. São Paulo. 2012; 75(2):92-96. Disponível em:http://www.scielo.br/scielo.php?script=sci_arttext\&pid=Sooo4274920120002000o $4 \& \operatorname{lng}=$ en $\& n r m=$ iso

22- Silva JFN. A aplicação da Toxina Botulínica e suas complicações. [Dissertação]. Instituto de Ciências Biomédicas de Abel Salazar da Universidade do Porto, 2orI. Disponível em:https://repositorioaberto.up.pt/bitstream/I0216/57190/2/Joana\%2oFilipa\%20Nog ueira\%2oda\%2oSilva\%20\%2opdf 
23- Soares CL. Aplicações não cosméticas da toxina botulínica em dermatologia, [Dissertação]. [Internet]. Faculdade De Medicina Da Universidade De Coimbra, 2015. Disponível em: https://estudogeral.sib.uc.pt/bitstream/ı0316/30500/I/Carolina\%2oSoares.pdf

24- Sposito MMM, Teixeira SAF. Toxina botulínica tipo a para bruxismo: análise sistemática. Acta Fisiátrica, São Paulo, v. 21, n. 4, 2014; p. 20I-204.

25- Sugano DM, Fernandez CL, Rehder JRC de L. Botulinum toxin for strabismus correction. [Internet] Rev. Bras. Oftalmol., São Paulo. 2013; 72(5):321-325. Disponível em: http://www.scielo.br/pdf/rbof/v72n5/o8.pdf

26- Tavares $\mathrm{F}$ da C. A toxina botulínica no tratamento da enxaqueca crônica, [Dissertação]. [Internet]. Instituto de Ciências Biomédicas Abel Salazar, Universidade do Porto - Porto, 2017. Disponível em: <https://repositorioaberto.up.pt/bitstream/ı0216/I09143/2/233310.pdf

27- Unno Ek, Sakato RK, Issy AM - Estudo comparativo entre toxina botulínica e bupivacaína para infiltração de pontos-gatilho em síndrome dolorosa miofascial crônica. Rev Bras Anestesiol 2005; 55:250-255.

28- Wannmacher L, Ferreira MBC. Enxaqueca: mal antigo com roupagem nova. Biblioteca Virtual Ministério da Saúde[Internet]. Brasília: Temas Selecionados. 2004; I(8):I-6. Disponível em: https://webcache.googleusercontent.com/search?q=cache:6Z4 ZiRqhPdkJ:https://sig arra.up.pt/fcnaup/pt/pub_geral.show_file\%3Fpi_gdoc_id\%3DI077526+\&cd= $\&$ \&hl=pt$\mathrm{BR} \& \mathrm{ct}=\mathrm{clnk} \& \mathrm{gl}=\mathrm{br}$ 
29- Wenzel RG - Pharmacology of botulinum neurotoxin serotype A. Am J HeathSyst Pharm 2004;61(suppl 6):s5-10.

30- Wohlfarth K, Kampe K, Bigalke H - Pharmacokinetic properties of different formulations of botulinum neurotoxin type A. Mov Disord 2004;19:s65-67. 